\title{
Immunoglobulin A response against Gardnerella vaginalis hemolysin and sialidase activity in bacterial vaginosis
}

\author{
Sabina Cauci, PhD, a Silvia Driussi, MD,b Rossella Monte, MS,a Paolo Lanzafame, MD,c Emanuele \\ Pitzus, MD,c and Franco Q uadrifoglio, PhDa \\ Udine, I taly
}

OBJECTIVE: The aim of this study was to investigate the correlation between the immunoglobulin A immune response to Gardnerella vaginalis hemolysin and sialidase activity in vaginal fluids from patients with bacterial vaginosis.

STUDY DESIGN: Nonpregnant women who were examined at a gynecologic clinic, in an age range of 18 to 62 years, were enrolled. The study population comprised 131 healthy volunteers, 32 women with bacterial vaginosis that was positive for immunoglobulin $A$ to Gardnerella vaginalis hemolysin, 40 women with bacterial vaginosis that was negative for immunoglobulin A to Gardnerella vaginalis hemolysin, and 19 women with Candida vaginitis. Bacterial vaginosis was diagnosed by clinical criteria and Gram stain.

RESULTS: Sialidase activity was present in $75 \%$ (54/72) of patients with bacterial vaginosis. Women having bacterial vaginosis and lacking a specific immunoglobulin A response had a significantly higher level of sialidase activity than patients who had an immune response against Gardnerella vaginalis hemolysin. Sialidase activity was detected in $87 \%$ (35/40) of the former subgroup of patients with bacterial vaginosis and in $59 \%$ $(19 / 32)$ of women of the latter subgroup. No sialidase activity was measured in patients with candidiasis. Specificity of the assay for healthy controls was 95\% (124/131 women without sialidase activity). CONCLUSIONS: Sialidases produced by Prevotella bivia and other microorganisms present in the microflora of patients with bacterial vaginosis are very likely a virulence factor not only by destroying the mucins and enhancing adherence of bacteria but also by impairing a specific immunoglobulin A immune response against other virulence factors such as cytotoxin from Gardnerella vaginalis. (Am J Obstet Gynecol 1998;178:511-5.)

Key words: Bacterial vaginosis, sialidase, Gardnerella vaginalis cytolysin, immune response, immunoglobulin A

Bacterial vaginosis is a polymicrobial syndrome characterized by a complex bacterial milieu; it is the most common disorder diagnosed in women who are examined at sexually transmitted disease clinics and is reported in about $20 \%$ of pregnant women. ${ }^{1}$ Although bacterial vaginosis is recognized as a risk factor in obstetrics and gynecology, ${ }^{2-7}$ little is known about the pathogenesis and the persistence of this synd rome.

Some bacteria involved in bacterial vaginosis are able to produce sialidases. Sialidases, or neuraminidases, have been implicated in the pathogenesis of many diseases; they catalyze the removal of terminal sialic acid residues

From the Department of Biomedical Sciences and Technologies, School of M edicine, University of Udine, azienda per i Servizi Sanitari M edio Friuli $n .4, b$ and the Microbiology Unit, Ospedale S. M aria della M isericordia.

Supported by grants from the University of Udine, Poly-Tech, Trieste, and Italian Consiglio $\mathrm{N}$ azionale delle Ricerche.

Received for publication June 23, 1997; revised September 2, 1997; accepted O ctober 9, 1997.

Reprint requests: Sabina Cauci, PhD, Department of Biomedical Scien ces and Techologies, Via Gervasutta 48, 33100 Udine, Italy. Copyright ( 1998 by M osby, Inc.

$0002-9378 / 98 \$ 5.00+0 \quad 6 / 1 / 86770$ from various glycoconjugates and play a role in bacterial nutrition, cellular interactions, and immune response evasion. ${ }^{8}$ Recently Briselden et al. ${ }^{9}$ demonstrated increased levels of sialidase activity in vaginal wash samples obtained from women with bacterial vaginosis. Sialidase activity correlates mainly with the presence of high titers of Prevotella spp. and Bacteroides spp. ${ }^{9}, 10$ Sialidase activity in vaginal fluids of women at 8 weeks after topical treatment with clindamycin was found to correlate with an increased risk of preterm birth and low birth weight by McGregor et al.11

From previous investigations we determined the biophysical properties of the hemolysin released by $\mathrm{G}$. vaginalis. $12,13 \mathrm{G}$. vaginalis hemolysin is a poreforming, cholesterol-binding cytolysin, which has maximal cytotoxic activity in physiologic conditions at the $\mathrm{pH}$ values of the vaginal secretions and is the sole identified and characterized virulence determinant of $G$. vaginalis. About half of the women with bacterial vaginosis show an anti-G. vaginalis toxin immunoglobulin A response. ${ }^{14}$ The two subgroups of bacterial vaginosis patients (anti-G. vaginalis toxin IgA positive and negative) are indistinguishable by normal criteria used to diagnose bac- 


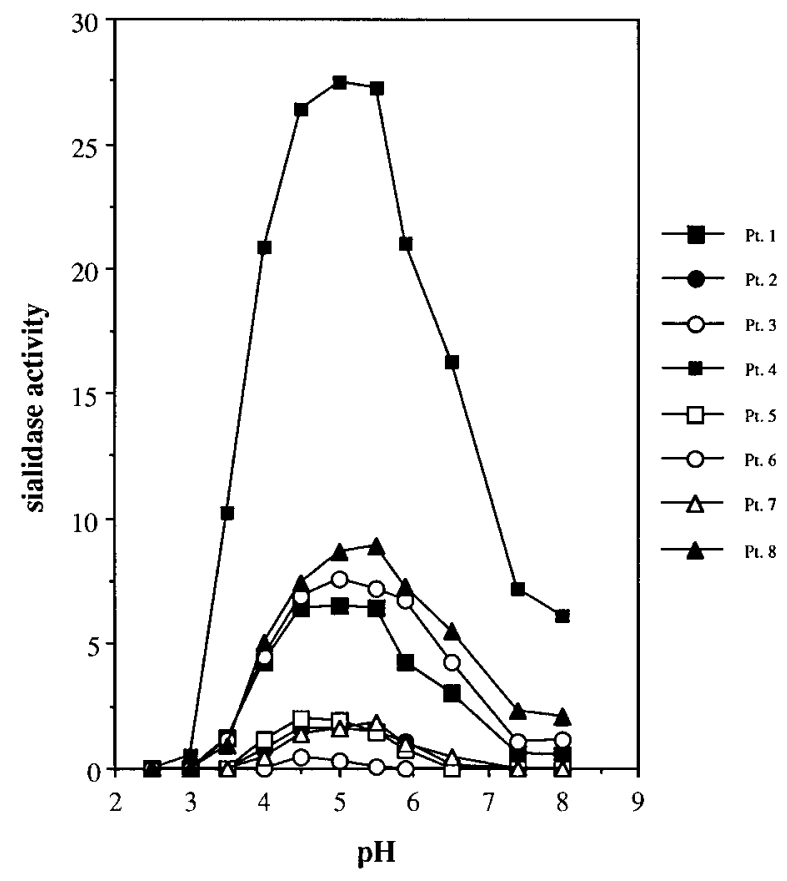

Fig. 1. Sialidase activity in vaginal washings of 8 patients with bacterial vaginosis as a function of $\mathrm{pH}$ of incubation buffer.

terial vaginosis. The aim of the current study was to assay vaginal fluid for the presence of the specific immune response against the toxin produced by G. vaginalis and evaluate the correlation of this parameter with the sialidase activity to determine whether the extracellular mucolytic enzymes are involved in a modulation of the host immune response.

\section{Material and methods}

Subjects and vaginal washings. Participants were recruited among women seeking care at the gynecologic care unit of Azienda per i Servizi Sanitari Medio Friuli, U dine, I taly. All patients were interviewed and examined by one clinician. On entry to the study oral informed consent was sought from all women, who were then interviewed for medical, obstetric, sexual, and contraceptive historic data. Women were excluded from the study for the use of oral or vaginal antibiotics in the past 2 weeks, pregnancy, menstruation or bleeding, sexual intercourse in the last 3 days, and in the case of the healthy control group for complaint of vaginal symptoms in the last 2 months.

By means of a cotton swab a sample of vaginal fluid was obtained from the lateral vaginal sidewall for evaluation of $\mathrm{pH}$ ( with paper strip $\mathrm{pH}$ range from 4.0 to 7.0 ) and rolled onto two glass slides for Gram stain evaluation and release of amine odor by the addition of $10 \%$ potassium hydroxide ("whiff test").

Vaginal wash specimens were prepared by inserting a sterile, nonlubricated speculum, washing the vaginal walls with $10 \mathrm{ml}$ of sterile saline solution, and removing the resultant suspension with a sterile syringe. The volume of the recovered specimen was recorded and ranged from 8.5 to $11 \mathrm{ml}$. The aliquots of fluids were stored at $-80^{\circ} \mathrm{C}$ until testing.

Bacterial vaginosis was defined clinically by the presence of homogeneous nonadherent vaginal discharge, odor in the presence of $10 \%$ potassium hydroxide, and vaginal $\mathrm{pH} \geq 4.7$. The vaginal $\mathrm{Gram}$ stain was evaluated with criteria developed by Nugent et al. ${ }^{15}$ Clue cells were rated as $>20 \%$ or $<20 \%$. The number of polymorphonuclear neutrophils was also recorded. Both clinical and Gram stain criteria (score $>6$ ) were required for enrollment in the group with bacterial vaginosis. Controls were healthy subjects without vaginal symptoms and with a score of 0 to 2 according to Nugent et al. Patients with candidiasis were clinically evaluated, and the diagnosis was supported by examination of Gram-stained slides.

Levels of hemolysin-specific IgA by enzyme-linked immunosorbent assay (ELISA). Anti-hemolysin IgA levels were detected by ELISA with 96-well microtiter plates ( flat bottom; Costar, Cambridge, Mass.) coated with purified G. vaginalis toxin as described previously.12, 14 Briefly, vaginal washings were added to duplicate wells and incubated at room temperature for 2 hours. Immunoglobulins that were reactive with the toxin were detected with alkaline phosphatase-conjugated sheep antihuman IgA (Silenus, Miami). The optical density was measured at $405 \mathrm{~nm}$ on a micro-ELISA plate reader. Positive samples had absorbance $>380$ milli-optical density units ( $m O D$ ) (cutoff value) after subtraction of the background value.

Sialidase test. To quantitatively assay the vaginal wash samples for sialidase activity, $100 \mu \mathrm{l}$ of the specimen was incubated on a microplate at room temperature and placed on a shaker with $100 \mu \mathrm{l}$ of the substrate $2-\left(3^{\prime}-\right.$ methoxyphenyl) - $\mathrm{N}$-acetyl-D-neuraminic acid (Sigma, St. Louis) dissolved in $0.05 \mathrm{~mol} / \mathrm{L}$ sodium acetate, $\mathrm{pH}$ 5.0.16 After 1 hour of incubation $50 \mu \mathrm{l}$ of $4 \mathrm{mmol} / \mathrm{L} 4-$ aminoantipyrine and $50 \mu \mathrm{l}$ of $6 \mathrm{mmol} / \mathrm{L}$ potassium ferricyanide were added. A duplicate sample lacking the substrate served as sample blank. Absorbances were read at $492 \mathrm{~nm}$. N onspecific absorbance as a result of the hydrolysis products contaminating the substrate was subtracted by duplicate blanks performed without vaginal washes. Specific activity was defined as nanomoles of methoxyphenol formed according to a standard curve obtained with pure methoxyphenol. All assays were performed in duplicate.

To determine optimal conditions for sialidase evaluation, a subset of samples was preliminarily examined at a different $\mathrm{pH}$ of incubation with the following buffers: 0.1 $\mathrm{mol} / \mathrm{L}$ sodium lactate at $\mathrm{pH} 2.5,3.0,3.5,4.0$, and $4.5 ; 0.1$ $\mathrm{mol} / \mathrm{L}$ sodium acetate at $\mathrm{pH} 4.5,5.0$, and $5.5 ; 0.1 \mathrm{~mol} / \mathrm{L}$ phosphate buffer at $\mathrm{pH} 5.9,6.5,7.4$, and 8.0. 
Statistical analysis. We compared sialidase activity levels in the bacterial vaginosis patient groups, in patients with candidiasis, and in healthy control subjects by analysis of variance, followed by the Bonferroni (modified least-significant difference test) and Tukey-B tests as appropriate. The Student t test for unpaired observations was used to compare the differences in mean sialidase levels between patient groups; t tests for paired samples were used to analyze the $\mathrm{pH}$ within-subject effect. A twotailed $p$ value $<0.05$ was considered to indicate statistical significance.

\section{Results}

A total of 222 women were screened for evaluation of sialidase activity. Thirty-two were patients with bacterial vaginosis showing an IgA-specific response to $G$. vaginalis hemolysin (anti-G. vaginalis toxin IgA-positive subgroup), whereas 40 patients with bacterial vaginosis had anti-G. vaginalis toxin IgA below the cutoff value of 380 mOD (specific IgA-negative subgroup). Two control groups were used: one of 19 patients with candidiasis without bacterial vaginosis and one of 131 healthy subjects without any vaginal infection.

Fig. 1 shows the variation in sialidase activity of the vaginal wash taken from 8 patients as a function of the $\mathrm{pH}$ value in the incubation buffer. The $\mathrm{pH}$ profile differed slightly in different patients, but the maximal enzymatic activity was al ways found in the $\mathrm{pH}$ range 4.5 to 5.5. At higher $\mathrm{pH}$ values sialidase activity was significantly reduced. At pH 5.9 an average $30 \%$ reduction of enzymatic activity was found. At pH 7.4 the reduction reached $90 \%$, with little activity still present at $\mathrm{pH}$ 8.0. Interestingly, low $\mathrm{pH}$ values, normally found in healthy women, drastically decrease sialidase activity. An average $80 \%$ reduction was measured at $\mathrm{pH} 3.5$, and at $\mathrm{pH} 3.0$ no activity was found. Paired test on 67 women showed no statistical difference between sialidase activity values at $\mathrm{pH} 4.5$ and 5.0 ( $p$ $=0.225$ ), whereas values at $\mathrm{pH} 5.9$ were statistically different from those at $\mathrm{pH} 5.0$ ( $p<0.001)$ and at $\mathrm{pH} 4.5$ ( $p<$ 0.001 ). No variation of response was found by increasing the incubation time with the sialic substrate up to 8 hours. pH 5.0 was chosen for evaluation of sialidase activity in vaginal washes of all the population studied.

When data for sialidase activity were examined by analysis of variance, followed by the Bonferroni (modified least-significant difference) and Tukey-B tests as appropriate, sialidase activity was highly associated with bacterial vaginosis ( $p<0.001$ ). No significant difference was found between patients with candidiasis and healthy control subjects ( $p=0.397$ ). Each subgroup of patients with bacterial vaginosis differed significantly from women with candidiasis and from healthy control subjects ( $p<$ 0.001 ). Moreover, the anti-G. vaginalis IgA-positive subgroup of patients with bacterial vaginosis differed significantly from the anti-G. vaginalis IgA-negative subgroup

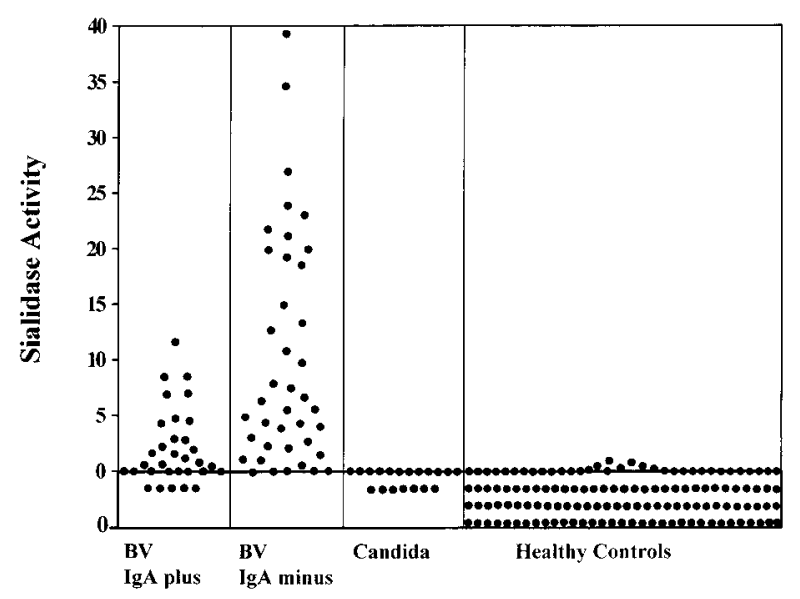

Fig. 2. Sialidase activity levels, measured at $\mathrm{pH} 5$, in vaginal washings of four groups of women: (1) anti-G. vaginalis toxin IgApositive subgroup of patients with bacterial vaginosis, (2) anti$G$. vaginalis toxin IgA-negative subgroup of patients with bacterial vaginosis, (3) group of women with candidiasis ( without bacterial vaginosis), and (4) control group of healthy women.

$(p<0.001)$. The mean value of sialidase activity in the I gA-negative subgroup (mean $\pm S D, 10.07 \pm 10.23 \mathrm{nmol}$ of methoxyphenol) was fivefold higher than that of the IgA-positive subgroup (mean $\pm \mathrm{SD}, 2.26 \pm 3.13 \mathrm{nmol}$ of methoxyphenol). Eighteen of 72 (25\%) women with bacterial vaginosis had no sialidase activity, 5 of 40 (12.5\%) in the IgA-negative subgroup and 13 of 32 (41\%) in the IgA-positive subgroup of women. None of the patients with candidiasis had sialidase activity. Seven of 131 (5\%) healthy subjects had detectable sialidase levels.

If a cutoff value of $0.5 \mathrm{nmol}$ of methoxyphenol is chosen, which corresponds visually to a pale pink coloration close to the detection limit in the spectrophotometric measurement (an absorbance value of 0.048 at $492 \mathrm{~nm}$ ), the sensitivity of the test is $69 \%$ (50/72) for all women having bacterial vaginosis, $85 \%(34 / 40)$ for the IgAnegative subgroup and $50 \%$ (16/32) for the IgA-positive subgroup of patients. Specificity of the test becomes $98 \%$ (two positive results with 131 healthy controls).

Fig. 2 shows the distribution of the sialidase levels in the four groups of women: (1) the anti-G. vaginalis toxin IgA-positive subgroup of patients with bacterial vaginosis, (2) the anti-G. vaginalis toxin IgA-negative subgroup of patients with bacterial vaginosis, (3) the group of women with candidiasis ( without bacterial vaginosis), and (4) the control group of healthy women.

\section{Comment}

Our previous detection of a specific IgA response to the $G$. vaginalis hemolysin in only $55 \%$ of women with positive cultures for $\mathrm{G}$. vaginalis ${ }^{14}$ raised the question of the mechanisms underlying the mucosal immune re- 
sponse in patients with bacterial vaginosis. We have looked for a virulence factor that differs from the $G$. vaginalis cytolysin to substantiate the existence of differences among patients with bacterial vaginosis. This study demonstrates that a high level of sialidase activity is associated with the absence of a local IgA immune response to $G$. vaginalis cytolysin.

Sialidases are implicated as virulence factors in a range of diseases such as peritonitis, septicemia, gastritis, and periodontal and respiratory disease. ${ }^{17}$ Sialic residues occupy the terminal positions of the 0 -glycosidic oligosaccharides found in mucins. Degradation of mucins present in the mucus gel layer by microbial pathogen enzymes is thought to be an important factor in the genesis of bacterial colonization of mucosal surfaces by compromising local host defenses and by providing nutrients to the invading microflora. $8,17,18$ The large number of sugar chains in mucins are considered to have protective functions against proteolysis of the inner core. Previous investigations have shown that sialidase activity is detectable in the vaginal fluid of patients with bacterial vaginosis and that anaerobic gram-negative rods such as Prevotella and Bacteroides spp. are the most probable source of sialidases.9, 10 Sialidase activity was found in all the P. bivia isolates but not in those of M ycoplasma homin is and Mobiluncus from patients with bacterial vaginosis. Noteworthy sialidase activity was present in washings of all women in whom oral therapy (with metronidazole or ampicillin) failed and in whom recurrent bacterial vaginosis developed 1 month after therapy. ${ }^{9}$ Moreover, sialidase activity, present after topical treatment with $2 \%$ clindamycin, correlates with prematurity and low birth weight, 11 supporting the notion that the production of sialidases by anaerobes is involved in the pathogenesis of bacterial vaginosis. O ur data suggest that sialidases may promote virulence not only by destroying the mucins and enhancing adhesion of bacteria but also by impairing the specific IgA immune response against virulence factors such as cytolysins. Other mechanisms such as the modification of the carbohydrate complexes involved in cellular recognition events and in aspecific antibacterial functions of secretory IgA may be compromised. 19,20 It is tempting to speculate that $G$. vaginalis colonization is relatively inoffensive until the host immune system is able to counteract the cytotoxic effects of its secreted cytolysin. This is in keeping with the observation that colonization by $G$. vaginalis in patients without anaerobic overgrowth may frequently be asymptomatic and transient. When synergistic growth of anaerobic bacteria occurs, microbial factors such as hydrolytic enzymes or exoproducts impair the immune response of the host, permitting the toxin to elude clearance and explicate all its virulence potential. Synergistic mechanisms between microorganisms involved in bacterial vaginosis have been hypothesized in the past, $21-23$ and very recently a symbiotic rela- tionship between $\mathrm{G}$. vaginalis and P. bivia involving ammonia utilization by the former was reported. 24

The profile of sialidase activity as a function of $\mathrm{pH}$ gives a rationale to the choice of the best conditions for enzyme detection in the vaginal fluids of women with bacterial vaginosis. It is of interest to note that at $\mathrm{pH}$ values below 4.5, which are normally found in healthy women, sialidase activity is rapidly reduced, and at pH 3.5 most of it is lost. This observation could be of relevance in the strategies adopted to eradicate bacterial vaginosis by local therapy. $\mathrm{H}$ owever, it must be reemphasized that sialidases are often one of several virulence factors secreted by bacteria and there are no clear examples that inhibition of secreted bacterial sialidases would halt a disease. 17

Bacterial vaginosis seems to have a multifactorial nature, and it is conceivable that the factors differ among patients leading to more or less severe outcomes. Our data show that a considerable portion of the patients have a high level of sialidase activity. This could impair the immune mucosal defense by cleaving the sialic acid residues of the IgA molecules, making them more accessible to protease degradation. This mechanism would explain the correlation found between high levels of sialidase activity and the absence of an IgA immune response. If future studies demonstrate that patients with a compromised local immune response show a higher risk of prematurity, bacterial invasion of the amniotic cavity, upper genital tract infections, and bacterial vaginosis recurrence, sialidase activity could become a valuable diagnostic marker for predicting the severity of the disease and helping in the choice of treatment.

We are grateful to Ms. Nunziata Verdolina, Azienda per i Servizi Sanitari Medio Friuli n. 4, Udine, for nursing, and to Dr. Maria Pia Francescato, Department of Biomedical Sciences and Technologies, U niversity of U dine, for biostatistical support. We acknowledge students Anna Knezevich and Giusi Zaina for their kind and invaluable assistance during the course of this project.

\section{REFERENCES}

1. Eschenbach DA. History and review of bacterial vaginosis. Am J O bstet Gynecol 1993;169:441-5.

2. Hillier SL, Martius J, Krohn M, Kiviat N, Holmes KK, Eschenbach DA. A case-control study of chorioamnionic infection and histologic chorioamnionitis in prematurity. N Engl J Med 1988;319:972-8.

3. Hillier SL, Nugent RP, Eschenbach DA, Krohn MA, Gibbs RS, $M$ artin $\mathrm{DH}$, et al. Association between bacterial vaginosis and preterm delivery of a low-birth-weight infant. N Engl J Med 1995;333:1737-42.

4. Gibbs RS. Chorioamnionitis and bacterial vaginosis. Am J O bstet Gynecol 1993;169:460-2.

5. Gravett MG, H ummel D, Eschenbach DA, H olmes KK. Preterm labor associated with subclinical amniotic fluid infection and with bacterial vaginosis. O bstet Gynecol 1986;67:229-37.

6. Rosene K, Eschenbach DA, Tompkins LS, Kenny GE, Watkins H. Polymicrobial early postpartum endometritis with facultative and anaerobic bacteria, genital mycoplasmas and Chlamydia tra- 
chomatis: treatment with piperacillin or cefoxitin. J Infect Dis 1986;153:1028-37.

7. Soper DE, Brockwell NJ, Dalton HP, Johnson D. Observations concerning the microbial etiology of acute salpingitis. Am J Obstet Gynecol 1994;170:1008-17.

8. Corfield AP. Bacterial sialidases-roles in pathogenicity and nutrition. Glycobiology 1992;2:509-21.

9. Briselden AN, Moncla BJ, Stevens CE, Hillier SL. Sialidases (neuraminidases) in bacterial vaginosis and bacterial vaginosisassociated microflora. J Clin Microbiol 1992;30:663-6.

10. Moncla BJ, Briselden AN, Hillier SL. Sialidase (neuraminidase) activity among gram-negative anaerobic and caprophilic bacteria. J Clin Microbiol 1990;28:422-5.

11. McGregor JA, French JI, Jones W, Milligan K, McKinney PJ, Patterson $E$, et al. Bacterial vaginosis is associated with prematurity and vaginal fluid mucinase and sialidase: results of a controlled trial of topical clindamycin cream. Am J O bstet Gynecol 1994;170:1048-60.

12. Cauci S, Monte R, Ropele M, Missero C, Not T, Quadrifoglio F, et al. Pore-forming and haemolytic properties of the Gardnerella vaginalis cytolysin. Mol Microbiol 1993;9:1143-55.

13. Cauci S, Monte R, Quadrifoglio F, Ropele M, Menestrina G. Ionic factors regulating the interaction of Gardnerella vaginalis hemolysin with red blood cells. Biochim Biophys Acta 1993;1153:53-8.

14. Cauci S, Scrimin F, Driussi S, Ceccone S, Monte R, Fant L, et al. Specific immune response against Gardnerella vaginalis hemolysin in patients with bacterial vaginosis. Am J Obstet Gynecol 1996;175:1601-5.

15. Nugent RP, Krohn MA, Hillier SL. Reliability of diagnosing bac- terial vaginosis is improved by a standardized method of Gram stain interpretation. J Clin Microbiol 1991;29:297-301.

16. Santer UV, Yee-Foon J, Glick MC. A rapid assay for neuraminidase: the detection of two differences in activity associated with virus transformation. Biochim Biophys Acta 1978;523:435-42.

17. Taylor G. Sialidases: structures, biological significance and therapeutic potential. Curr O pin Struct Biol 1996;6:830-7.

18. Gahmberg CG, Tolvanen M. Why mammalian cell surface proteins are glycoproteins. Trends Biochem Sci 1996;21:308-11.

19. McGhee JR, M estecky J, Dertzbaugh MT, Eldridge JH, H irasawa $\mathrm{M}$, Kiyono $\mathrm{H}$. The mucosal immune system: from fundamental concepts to vaccine development. Vaccine 1992;10:75-88.

20. Pilatte Y, Bignon J, Lambré CR. Sialic acids as important molecules in the regulation of the immune system: pathophysiological implications of sialidases in immunity. Glycobiology 1993;3:201-17.

21. Pheifer TA, Forsyth PS, Durfee MA, Pollock HM, Holmes KK. Nonspecific vaginitis. Role of $\mathrm{H}$ aemophilus vaginalis and treatment with metronidazole. N Engl J Med 1978;298:1429-34.

22. Chen KCS, Forsyth PS, Buchanan TM, Holmes KK. Amine content of vaginal fluid from untreated and treated patients with nonspecific vaginitis. J Clin Invest 1979;63:828-35.

23. Spiegel CA, Amsel R, Eschenbach $D$, Schoenknecht $F$, Holmes KK. Anaerobic bacteria in nonspecific vaginitis. N Engl J Med 1980;303:601-6.

24. Pybus V, Onderdonk AB. Evidence for a commensal, symbiotic relationship between Gardnerella vaginalis and Prevotella bivia involving ammonia: potential significance for bacterial vaginosis. J Infect Dis 1997;175:406-13. 